УДК 37.002

\title{
ПРАКТИЧЕСКОЕ ПРИМЕНЕНИЕ ПРИЕМОВ КРЕАТИВНОГО ПИСЬМА НА СТАРШЕМ ЭТАПЕ ОБУЧЕНИЯ
}

\author{
Щепина Мария Александровна \\ аспирант \\ ФГБОУ ВО «НГПУ им. К. Минина»
}

\begin{abstract}
Аннотация. В данной статье в процессе развития коммуникативной иноязычной компетенции учащихся старших классов рассматривается роль творческого письма, или креативного письма («Creative writing»), приводятся подготовительные творческие упражнения, направленные на конечный результат - написание одного из видов креативного письма, очерк (на основе интервью).

Ключевые слова: коммуникативная иноязычная компетенция, креативное письмо, тематическое письмо (интервью), очерк, языковые навыки, творческие способности.
\end{abstract}

\section{PRACTICAL APPLICATION OF CREATIVE WRITING METHODS AT THE SENIOR STAGE OF LEARNING}

\section{Shchepina Maria Alexandrovna}

\begin{abstract}
In this article, in the process of developing the communicative foreign language competence of high school students, the role of creative writing is considered, preparatory creative exercises are given aimed at the result - writing one of the types of creative writing, an essay (based on interview).
\end{abstract}

Key words: communicative foreign language competence, creative writing, thematic writing (interview), essay, language skills, creativity.

Один из популярных на западе методов - обучение иностранному языку посредством творческого письма, или креативного письма («Creative writing»). В свете современной парадигмы образования использование данного метода наиболее актуально, так как, согласно ФГОС, задача педагогов - воспитание, социально-педагогическая поддержка становления и развития высоконравственного, ответственного, а главное творческого, инициативного 
гражданина России [1, с. 31]. Учитель должен находиться на заднем плане, лишь помогать, направлять детей. Школьник должен научиться самостоятельно заниматься, самоорганизовываться, добиваться успеха, овладеть универсальными учебными действиями. Креативное письмо помогает развивать данные компетенции.

Творческая письменная речь учащегося, являясь мотивированной, целенаправленной и структурированной, - это создание письменного произведения, которое не может осуществляться без развитых творческих способностей, в частности, способности к творческому мышлению и воображению, а также иноязычных знаний, навыков и умений. Творческая письменная речь включает различные виды письменной речи, такие как:

- Изложение с элементами сочинения;

- Сочинения в различных композиционно-речевых формах;

- Рефлексивное письмо;

- Тематическое письмо (интервью, отчет, сообщение);

- Личное письмо (журнал, дневник, воспоминание) [2, с. 3].

На уроках иностранного языка необходимо креативно подходить к обучению учащихся английскому языку и развивать их творческие способности вместе с языковыми навыками [3, 17 с.]. Для этого, опираясь на методику креативного письма, учитель использует упражнения, имеющие творческий или полутворческий характер, для того, чтобы учащиеся старших классов смогли составить собственный письменный текст.

Опираясь на опыт преподавания в школе с углубленным изучением английского языка, приведем пример урока, цель которого состояла в том, чтобы учащиеся написали один из видов креативного письма - очерк на основе интервью с «вымышленным» писателем. При изучении темы «Тhe Pleasure of Reading» использовались типы заданий, такие как «корзина идей», «кластер», «инсерт», «синквейн», чтобы подготовить учащихся к написанию очерка в газету.

Согласно ФГОС, учащиеся сами должны определить цель и тему урока. Для этого начинаю урок со следующего задания, которое носит дифференцированный характер. Работа выполняется в парах, которые создаются с учетом способностей учащихся. Суть задания в следующем: даются высказывания о чтении, и две пары учащихся соединяют начало и конец английского высказывания (базовый уровень задания), а три пары учащихся соединяют английские высказывания и их русские переводы 
(повышенный уровень) (табл. 1). Прочитав получившиеся высказывания, учащиеся сами выводят тему урока «Reading».

\section{Таблица 1}

Авторы и их высказывания

\begin{tabular}{|c|c|c|}
\hline Английские высказывания & Русские высказывания & $\begin{array}{c}\text { Автор } \\
\text { высказывания }\end{array}$ \\
\hline $\begin{array}{l}\text { The books that help you the } \\
\text { most are those which make you } \\
\text { think the most. }\end{array}$ & $\begin{array}{c}\text { Самые ценные книги те, которые } \\
\text { заставляют Вас много думать. }\end{array}$ & Parker \\
\hline $\begin{array}{l}\text { I divide all readers into two } \\
\text { classes: those who read to } \\
\text { remember and those who read to } \\
\text { forget. }\end{array}$ & $\begin{array}{c}\text { Я разделяю читателей на два } \\
\text { класса: на тех, кто читает, чтобы } \\
\text { обогатиться, и на тех, кто читает, } \\
\text { чтобы забыться. }\end{array}$ & Edward Phelps \\
\hline $\begin{array}{l}\text { Some books leave us free, and } \\
\text { some books make us free. }\end{array}$ & $\begin{array}{c}\text { Одни книги оставляют нас } \\
\text { свободными от мыслей, другие - } \\
\text { делают нас свободными людьми. }\end{array}$ & Emerson \\
\hline $\begin{array}{l}\text { A man ought to read just as } \\
\text { inclination leads him; for what } \\
\text { he reads as a task will do him } \\
\text { little good. }\end{array}$ & $\begin{array}{c}\text { Человек должен читать то, что ему } \\
\text { хочется, ибо чтение по } \\
\text { принуждению приносит мало } \\
\text { пользы. }\end{array}$ & Samuel Johnson \\
\hline $\begin{array}{l}\text { A classic is something that } \\
\text { everybody wants to have read } \\
\text { and nobody wants to read. }\end{array}$ & $\begin{array}{c}\text { Классика - это то, что каждый } \\
\text { хочет иметь в багаже } \\
\text { прочитанного, но никто не хочет } \\
\text { читать. }\end{array}$ & Twain \\
\hline
\end{tabular}

Далее, чтобы подготовить учеников к речевой деятельности, используется прием «корзина идей», который позволяет выяснить, что знают и думают обучающиеся по обсуждаемой теме. Учащиеся выражают свои мысли, отвечая на вопрос «Why do people like reading?»

Основной этап урока начинаю с приема «кластер», который является отражением нелинейной формы мышления. Работа выполняется в группах. Время выполнения работы - четыре минуты. В центре кластера располагается ключевое понятие - «книга», ребята отвечают на вопрос: «На что вы обращаете внимание, когда хотите прочитать книгу» и пишут словаассоциации, ответы. Такое упражнение позволяет аккумулировать все знания учащихся и является переходом к следующим заданиям. Так как далее по сценарию урока ребят ждет интервью с «писателем», обращаю их внимание 
именно на этот ответ: «Когда я хочу прочитать книгу, я обращаю внимание на автора» (рис. 1).

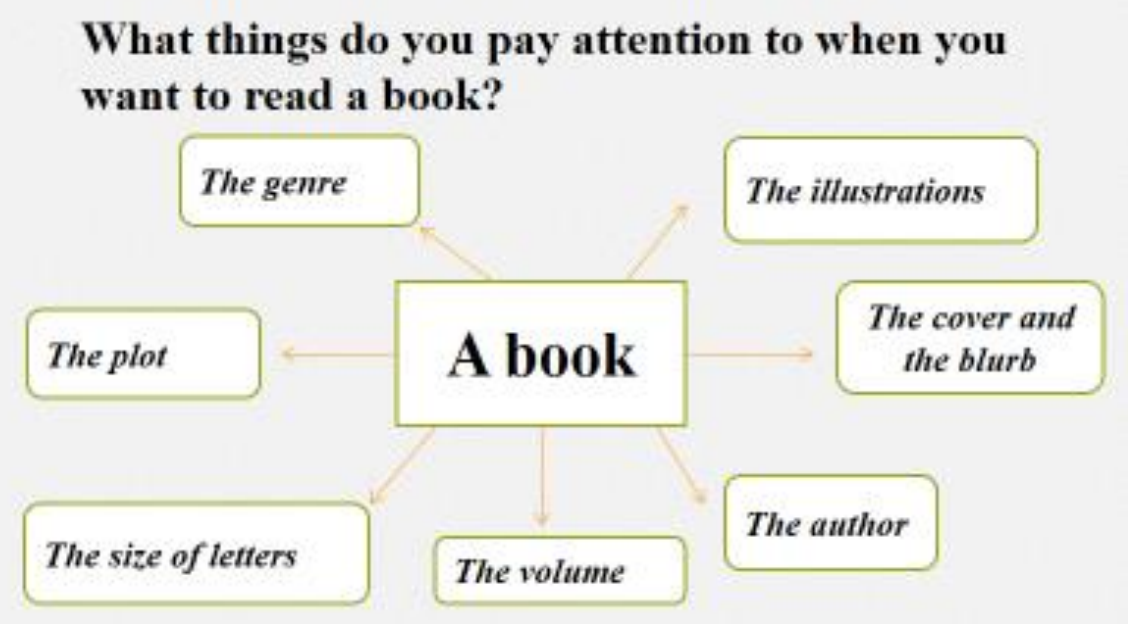

Рис. 1. «Кластер» - ключевое понятие «книга»

Следующее задание - соединить имена писателей с их произведениями выполняется с помощью интерактивной доски (табл. 2).

Таблица 2

\section{Писатели и их произведения}

\begin{tabular}{|c|c|}
\hline Agatha Christie & Murder on the Orient Express \\
\hline Christopher Paolini & Eragon \\
\hline J. R. R. Tolkien & The Lord of the Rings \\
\hline William Shakespeare & Hamlet \\
\hline Charles Dickens & Oliver Twist \\
\hline J. K. Rowling & Harry Potter \\
\hline
\end{tabular}

В ролевой игре у каждого учащегося своя роль: писатель, ведущий программы, остальные учащиеся - журналисты, которые могут задавать вопросы «вымышленному» писателю. Во время интервью учащиеся заполняют таблицу, еще один из приемов «инсерт» и одно из УУД: умение трансформировать информацию из одной формы в другую (текст-таблица). После интервью ученики, играющие роль журналистов, обсуждают вопросы, которые можно задать, чтобы получить информацию, неосвещенную в диалоге «ведущей» и «писателя». 
Продуктивным заданием выступает создание очерка о писателе от лица журналиста, присутствующего на интервью. Задание - дифференцированное: можно выбрать написать рассказ по плану (табл. 3), подготовленному мною заранее (базовый уровень), можно без плана (повышенный уровень).

Таблица 3

\section{План очерка (базовый уровень)}

\begin{tabular}{|ll|}
\hline 1. & Education \\
\hline 2. & His first book (name, genre, main character, publication) \\
\hline 3. & His favourite writers \\
\hline 4. & His attitude to reading \\
\hline 5. & His attitude to fantasy books \\
\hline 6. & His advice \\
\hline
\end{tabular}

Заканчивается урок «сиквейном», излагающий материал на определенную тему.

\section{Reading}

Interesting and exciting.

Grips, entertains, teaches.

Paints our world in colours.

A good friend.

Домашнее задание состоит в написании очерка о писателе Paolini в газету. С данным видом креативного письма учащиеся старших классов легко справятся после выполнения подготовительных упражнений, где кроме развития языковых навыков, воображения и логики, школьники замотивированы работать в команде.

Поэтому, чем больше разнообразных заданий используется, тем эффективнее результаты. Рассмотренные задания служат своеобразным переходом между структурированными упражнениями начального звена к творческим заданиям продвинутого уровня [4, с. 79]. Они подготавливают учащихся к написанию сложных видов креативных письменных работ.

При обучении креативному письму учащиеся формулируют мысли в письменной форме, расширяя знания и кругозор, овладевая культурой и интеллектуальной готовностью создавать содержание письменного текста [5, с. 129]. Применение творческих заданий на уроках английского языка является эффективным и продуктивным методом формирования творческой иноязычной письменной речи. 
Считаем, что в современных школах учителя должны стараться больше времени уделять творческой стороне речи учащихся. Данная задача является неотъемлемой составляющей роли учителя иностранного языка.

\section{Список литературы}

1. Федеральный государственный образовательный стандарт основного общего образования / Министерство образования и науки Российской Федерации. - М.: Просвещение, - 2011. - с. 31.

2. Принципы обучения иностранному языку: учебное пособие / под редакцией Е.И. Пассова, Е.С. Кузнецовой. - Воронеж: НОУ «Интерлингва», 2002. - 40 c.

3. Винокурова Н.К. Развитие творческих способностей учащихся. - М: Педагогический поиск, - 1999. - 17 с.

4. Рогова Г.В. Методика обучения иностранным языкам в средней школе / Г.В. Рогова, Ф.М. Рабинович. - Минск: Просвещение, - 1991. - 287 с.

5. Вторушина Н.Ю. Письмо и письменная речь в обучении иностранному языку // Альманах современной на уки и образования. Тамбов: Грамота, - 2010. - №1(32). - В 2 ч. - Ч. 2. - С. 129-132.

(C) М.А. Щепина, 2021 